\title{
UNIVERSITY COLLEGE OF SWANSEA NEW CHEMISTRY LABORATORIES
}

\begin{abstract}
TEW chemistry laboratories were opened at University College, Swansea, on May 1 by Sir Alexander Todd. When, in 1920, a department of chemistry was established by J. E. Coates in Swansea, accommodation was provided in temporary buildings the useful life of which was expected to be ten years. In fact, the Chemistry Department has occupied this accommodation until this year, when the new laboratories became available.

The building consists of three major units: a north wing with teaching laboratories; a south wing with research laboratories; and a central spine which contains the lecture theatres, main stores and central services. Accommodation is on three floors, with a total area of 66,000 sq. ft.

The three floors of the teaching wing are essentially the same. Each consists of one general and one honours laboratory accommodating 60 and 48 students respectively, and built on either side of common preparation and balance rooms. The ground-floor honours laboratory has special facilities for organic chemistry; the first and second floor honours laboratories are specially designed for physical and inorganic chemistry respectively. In the general laboratories, each working space is provided with two sets of lockers so that a total of 360 elementary students can be accommodated during one session.

The research wing contains principally staff rooms and research laboratories. The ground-floor is devoted to organic chemistry and has six staff rooms facing south and two six-man research laboratories with an interconnecting service laboratory facing
\end{abstract}

north. The arrangements on the first floor (physical chemistry) and the second floor (inorganic chemistry) are similar. This wing also contains professors' suites, a departmental library with book-stack, microfilm room and reading room, and a seminar room.

There are a number of general facilities for both teaching and research in the central spine. These include two lecture theatres, both stepped, windowless and mechanically ventilated, with seating for 320 students in the larger theatre and 105 students in the smaller one; at second-floor level above the large lecture theatre is a combined lecture theatre and examination room seating 120 students; there are three main stores directly above each other in the central spine and connected by a goods lift. In addition, in the central spine, there is an engineering workshop, an instrument room and separate workshops for glass-blowing and for electronics. A semitechnical area is situated under the small lecture theatre and is equipped for operations such as fractionation and solvent extraction on a pilot plant scale. A number of rooms with special facilities open off the semi-technical area : a cold room; a walk-in fume cupboard; a fire and flood laboratory; a centrifuge room and a constant-temperature room. The first floor of the central spine included a microchemistry laboratory, dark rooms and special laboratories for infra-red and Raman spectroscopy. On the second floor are a radio chemistry laboratory, special instrumentation rooms and a liquid-air plant.

Benches in the laboratories have been designed to give flexibility and ease of access to services for

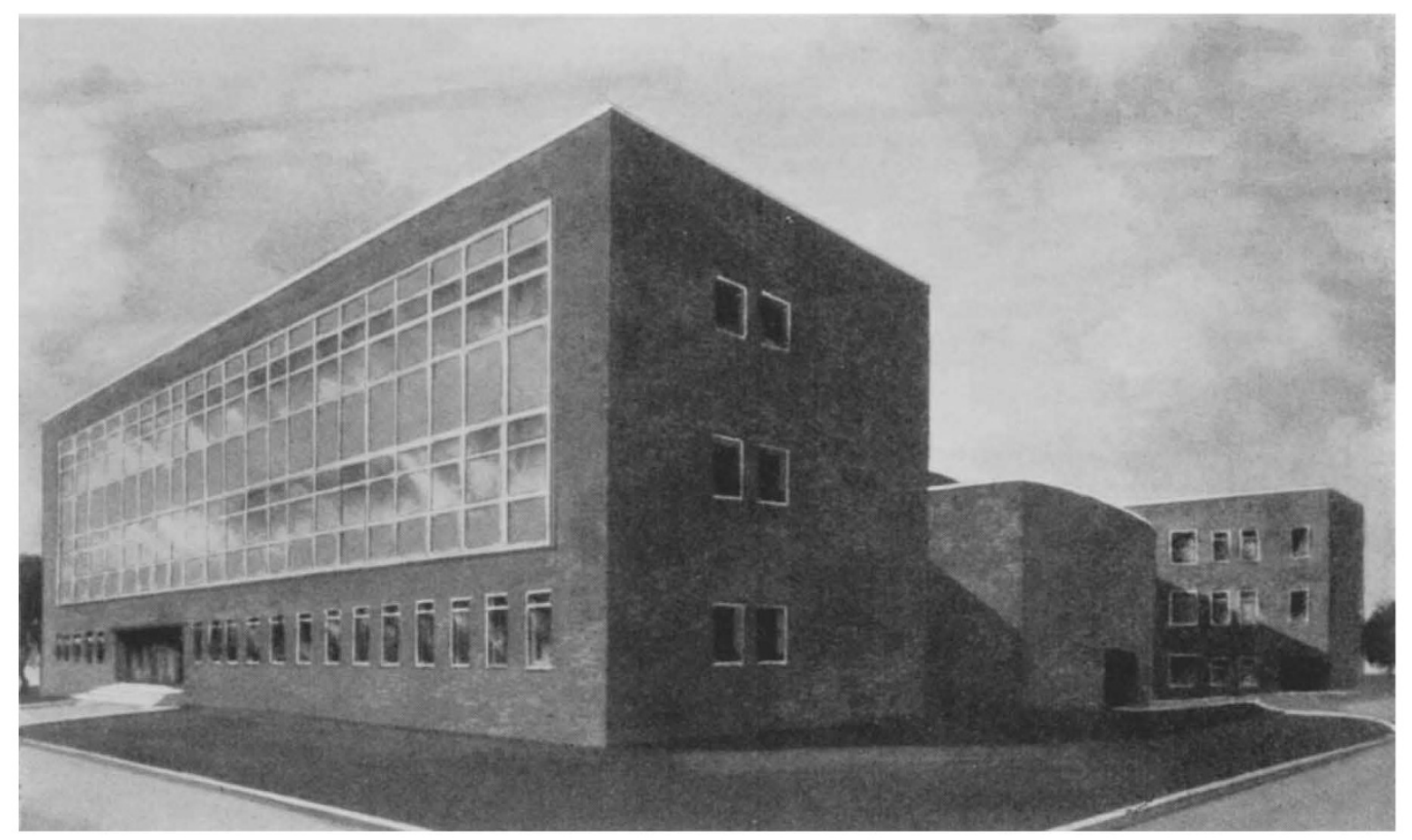

Fig. 1. New Chemistry Laboratories, University College of Swansea 
maintenance. Most of the benches, both of the island and wall type, have tops supported by cantilever brackets which fit into specially designed service stands fixed to the walls and floor. Underbench cupboard and drawer units then slide into a position below the bench tops and conceal the service racks. In the research laboratories the tops can be fixed at either standing or sitting height, or can be removed entirely leaving only the stands and associated services. The service racks are formed by a number of metal supports spaced at approximately 3 -ft. centres and connected at bench-level by a 9 -in. wide horizontal teak strip and a 6 -in. deep teak facia. Curved brackets are fixed to the metal strands which support the service pipes, from which outlets are taken at suitable positions. Where a concentration of service is required, plumbing has been simplified by the use of service towers, which results in a clear bench top and a generally neater appearance. In the physical chemistry research laboratories the bench tops and cupboards form movable integral units. All services are available along the walls, with electrical services also available from ceiling outlets. This gives great flexibility in the arrangement of the laboratories.

Bench tops are of Burma teak (Tectona grandis); all other exposed timber and veneers are of West African mahogany. Teak has also been used throughout as flooring in laboratories. Reagent shelves have been covered with white 'Vitrolite' and the working tops of fume cupboards formed from a sheet of armour-plated glass.

The number of students taking courses in chemistry now exceeds 250, including 37 honours students and 26 research students and fellows. These numbers are expected to increase considerably in the next five years, during which period the College is planning to increase the number of students from 1,500 to 3,000 .

The new facilities make possible very substantial expansion of the research programme in Swansea. As it is, the work of the Department covers a wide range of interest. There is a group working with D. A. Long in the field of molecular spectroscopy with special emphasis on Raman studies. Other groups are concerned with the infra-red spectroscopy of amides (H. E. Hallam et al.), the kinetics of nitrosation reactions (G. Stedman et al.) and solid-state chemistry (K. J. Gallagher et al.). The organic chemists are largely concerned with natural products. This work, which is under the general direction of Prof. C. $\mathbf{H}$. Hassall and Dr. R. F. Curtis, involves work on peptides, cardenolides and alkaloids. A major investigation, dealing with the pathways of biosynthesis of complex phenolic compounds, combines techniques of organic chemistry with others drawn from the relatively young field of chemical genetics. There are also investigations in the field of steroid chemistry (G. H. R. Summers et al.) with particular emphasis on reaction mechanisms.

\section{SCIENCE AND INDUSTRY_THE PROBLEM OF COMMUNICATION}

A CONFERENCE, organized by the Department of Scientific and Industrial Research and held in Swansea during April 18-19, had as its primary object the critical examination of present-day methods of disseminating scientific and technical knowledge. Both the papers and the lively discussions which followed indicated the growing concern in scientific and industrial circles with the many-sided nature of this problem.

Opening the conference, Lord Brecon, Minister of State for Welsh Affairs, emphasized the relation between the growth of scientific knowledge, the resultant industrial innovation and the growth of industry. His reference to the time-lag between technical advance and industrial use of new techniques and new materials was echoed by several speakers.

Nine papers were briefly presented to enable delegates themselves to participate in the frank and critical appraisal of the problems and solutions as presented. The first paper, by W. S. Robertson, chief executive of the Scottish Council for Develop. ment and Industry, reminded delegates that as the rolume of available information multiplied there was a proportionate increase in the difficulty of condensing and making that information effectively available to those who could use it. The answer to the increasing volume of literature, it was suggested, might lie in the development of mechanized recording and retrieval systems, but Mr. Robertson maintained that there was still nothing quite so effective as personal contact for passing on new ideas and knowhow. He thought that scientific and technical, as well as commercial, people should be encouraged to travel more widely and more frequently, and he con- demned the inhibiting parochial attitude of many firms which restricted the development of this most useful means of exchanging ideas.

Dr. D. J. Urquhart, director of the National Lending Library for Science and Technology, also emphasized personal contact, and likened the seeker after scientific information to the stranger in a vast, growing, changing eity, the maps of which became out of date almost as soon as they were published. The best and almost only way of reaching an objective quickly was to ask other people working in the specified field. Dr. Urquhart stressed the assistance that libraries and information scientists could provide in making these contacts and warned the conference that existing facilities were inadequate. Quoting Wales as an example, he pointed out that there were only two public libraries with a reasonable holding of scientific periodical literature. The educational aspects of the problem were discussed in the paper by Dr. M. R. Hopkins, senior lecturer in physies at Swansea. He criticized the attitude of narrow utilitarianism which leads to a programme of teaching preoccupied with its immediate purpose. He sug. gested that the training of every educated man and woman should include some teaching of the funda. mental principles of scientific thought, and that both scientists and non-scientists should be educated in the basic skills of communication. Speakers from both platform and floor supported this view; it was pointed out that not one university department specializing in documentation studies existed in Britain. A large increase in the British research effort in this field and the allied one of information retrieval was called for. Following Dr. Hopkins several speakers demanded better facilities for 